\title{
O DISCURSO DESENVOLVIMENTISTA, A PRÁTICA ORÇAMENTÁRIA E A EFETIVIDADE DO ESTADO ENQUANTO INDUTOR DO DESENVOLVIMENTO: UM ESTUDO NO ESTADO DE SANTA CATARINA/BRASIL
}

\author{
Maurício Vasconcellos Leão Lyrio ${ }^{1}$ \\ Rogério João Lunkes ${ }^{2}$
}

\begin{abstract}
RESUMO: O presente trabalho se insere no contexto da discussão da intervenção do Estado na economia, por meio de um estudo desenvolvido no âmbito do Estado de Santa Catarina/Brasil. Em 2005, em atendimento à Lei Complementar 284, o Governo do Estado estabeleceu o chamado 'Plano Catarinense de Desenvolvimento', composto por um conjunto de diretrizes e estratégias que visam orientar a ação governamental e fomentar o desenvolvimento no Estado até o ano de 2015. Nesse sentido, o estudo tem como objetivo identificar e analisar a relação entre a aplicação de recursos públicos, via orçamento do Estado, e os reflexos desta aplicação, por meio da comparação entre os recursos alocados nas políticas constantes no Plano Catarinense de Desenvolvimento e o impacto destes no Produto Interno Bruto - PIB do Estado de Santa Catarina. No que tange ao enquadramento metodológico, o presente estudo adota abordagens tanto qualitativa - no momento da análise do Plano Catarinense de Desenvolvimento, quanto quantitativa - no momento da análise do orçamento do Estado. Como resultados, evidenciou-se uma mescla de políticas Keynesianas e Schumpeterianas no Plano Catarinense de Desenvolvimento, e uma tendência positiva tanto na evolução dos recursos alocados ao Plano de Desenvolvimento, quanto na evolução do Produto Interno Bruto do Estado.
\end{abstract}

Palavras-chave: Setor Público; Desenvolvimento Econômico; Orçamento por Desempenho.

\section{THE DEVELOPMENT DISCOURSE, THE BUDGETARY PRACTICE AND EFFECTIVENESS OF THE STATE AS PROMOTER OF DEVELOPMENT: A STUDY IN THE STATE OF SANTA CATARINA / BRAZIL}

\begin{abstract}
This work is in the context of the discussion of state intervention in the economy, through a study conducted in the State of Santa Catarina / Brazil. In 2005, in response to Complementary Law 284, the State Government established the so-called 'Plano Catarinense de Desenvolvimento', composed by a set of guidelines and strategies to guide government action and foster development in the state by the year 2015. In this sense, the study aims to identify and analyze the relationship between the use of public funds via the state budget, and reflections of this application, by comparing the proceeds allocated to the policies contained in the Development Plan of Santa Catarina and the impact of these Gross Domestic Product - GDP of the State of Santa Catarina. Regarding the methodological framework, this study adopts both qualitative approaches - when analyzing Santa Catarina Development Plan, and quantitative - when analyzing the state budget. As a result, there was a mix of Keynesian and Schumpeterian policies in the Development Plan of Santa Catarina, and a positive trend both in the evolution of resources allocated to the Development Plan and in the evolution of the Gross Domestic Product of the State.
\end{abstract}

Key-words: Public Sector; Economic Development; Performance-based Budgeting.

\footnotetext{
${ }^{1}$ Professor do curso de graduação em administração da SOCIESC/FGV e do curso de Pós-Graduação em Administração certificado pela FGV. E-mail: mauriciovll@ gmail.com.

${ }^{2}$ Professor Associado I da Universidade Federal de Santa Catarina (UFSC). E-mail: rogeriolunkes@hotmail.com.
}

Recebido em 07/08/2013

Aceito em 22/11/2013 
O discurso desenvolvimentista, a prática orçamentária e a efetividade do Estado enquanto

indutor do desenvolvimento: um estudo no estado de Santa Catarina/Brasil.

\section{INTRODUÇÃO}

A discussão sobre o desenvolvimento capitalista enquanto processo histórico e interpretativo envolve uma relação entre economia e política em um jogo de poder, no qual um dos aspectos inerentes ao desenvolvimento é justamente o grau de intervenção do Estado na economia. Os economistas clássicos já discutiam a questão da intervenção do Estado na economia. Smith (1997) aborda a questão ao discutir a divisão do trabalho, Ricardo (1997) ao tratar das vantagens comparativas do comércio entre países e Marx (1984), ao abordar o desenvolvimento capitalista em escala mundial.

As teses propostas pelos economistas clássicos foram desenvolvidas em diferentes períodos da expansão do capitalismo mundial, tanto do ponto de vista comercial quando industrial. Apesar disso, o debate entre os clássicos levanta algumas questões importantes referentes ao problema das relações entre os Estados, as moedas e a riqueza desigual das nações. A respeito desse problema, Fiori (1999) alega que a escola liberal propõe permanentemente autonomizar o desenvolvimento capitalista a despeito da intervenção do Estado, mas que esta (a escola liberal) reconhece a importância da influência política. $\mathrm{O}$ autor argumenta, ainda, que a abordagem Marxista trata da relação entre o poder político e o capital financeiro na competição entre os Estados nacionais e que a abordagem da escola mercantilista, da mesma forma, reconhece a relação direta entre o poder político, o manejo das moedas e a expansão e distribuição desigual da riqueza (FIORI, 1999).

Polanyi (1980), por sua vez, reconhece um 'duplo movimento' provocado pela ação de dois princípios de organização e sociedade: “um, o princípio do liberalismo econômico, que objetiva estabelecer um mercado auto-regulado, e o outro, o princípio da proteção social, cuja finalidade é preservar o homem e a natureza, além da organização produtiva" (POLANYI, 1980, p. 139).

A presente pesquisa se insere neste contexto da discussão da intervenção do Estado na economia, por meio de um estudo desenvolvido no âmbito do Estado de Santa Catarina / Brasil. Em 2005, em atendimento à Lei Complementar 284, o Governo do Estado estabeleceu o chamado 'Plano Catarinense de Desenvolvimento', composto por um conjunto de diretrizes e estratégias que visam orientar a ação governamental e fomentar o desenvolvimento no Estado até o ano de 2015. O estabelecimento desse plano de desenvolvimento levanta uma inquietação em relação à sua efetividade enquanto estratégia de desenvolvimento, o que leva 
Revista Economia e Desenvolvimento, v. 25, n. 2, 2013.

à seguinte pergunta de pesquisa: "o Plano Catarinense de Desenvolvimento efetivamente vem sendo capaz de induzir o desenvolvimento econômico no âmbito do Estado?”

Para responder a essa questão de pesquisa, o presente artigo buscará como objetivo geral, identificar e analisar a relação entre a aplicação de recursos públicos via orçamento do Estado, e os reflexos desta aplicação, por meio da comparação entre os recursos alocados nas políticas constantes no Plano Catarinense de Desenvolvimento e o impacto destes no Produto Interno Bruto - PIB do Estado de Santa Catarina.

A relevância do estudo se dá pelo entendimento por parte dos autores, da importância do orçamento público enquanto indutor do desenvolvimento. Uma vez que os recursos públicos são alocados de forma adequada, acredita-se que estes ajudarão no desenvolvimento econômico do Estado, via melhoria das condições para desenvolvimento das relações de mercado e via melhoria das condições de vida da população.

Após essa seção introdutória, a seção 2, referente ao referencial teórico, buscará tratar das considerações sobre o papel do Estado para o desenvolvimento econômico para, em seguida, tratar do orçamento público no Brasil, bem como dos preceitos de orçamento por desempenho; a seção 3 buscará apresentar os procedimentos metodológicos adotados na condução do estudo realizado no âmbito do Estado de Santa Catarina; A seção 4 apresentará as diretrizes e estratégias constantes no Plano Catarinense de Desenvolvimento e analisará a evolução dos recursos públicos aplicados às políticas constantes neste plano. Finalmente, realizará uma comparação entre a evolução dos recursos alocados e a evolução do PIB no Estado. A seção 5 apresentará as conclusões obtidas no estudo.

\section{REFERENCIAL TEÓRICO}

O referencial teórico do estudo aqui apresentado envolverá uma discussão sobre o papel do Estado para o desenvolvimento econômico, e, em seguida, apresentará uma breve discussão sobre orçamento público no Brasil e o orçamento por desempenho, também conhecido como Performance-based Budgeting - PBB.

\subsection{Considerações sobre o papel do Estado para o desenvolvimento}

A discussão sobre o desenvolvimento e o papel do Estado e do mercado nesse contexto é antiga. Enquanto os adeptos das ideias liberais falavam de um Estado mínimo e de uma desregulamentação, para que o próprio mercado encontre seu equilíbrio dinâmico, os 
O discurso desenvolvimentista, a prática orçamentária e a efetividade do Estado enquanto indutor do desenvolvimento: um estudo no estado de Santa Catarina/Brasil.

adeptos de ideias intervencionistas já vinham argumentando sobre as limitações da capacidade do mercado de promover desenvolvimento econômico e acumulação regular de capital. Boyer (1999) argumenta que para o século que se inicia o desenvolvimento passará, necessariamente, por uma revisão do papel do Estado, com vistas a uma relação mais equilibrada entre este e o mercado. A solução passaria por um processo de compensação das falhas do mercado por meio de intervenções públicas adequadas, bem como por uma busca de complementaridade e pela criação de instituições que intermediam essa relação, como por exemplo, associações e parcerias.

Tratando dessa questão no âmbito da América Latina, Iglesias (2010) discute o papel do Estado na região, discorrendo sobre seus paradigmas principais, a saber, o paradigma da CEPAL e o consenso de Washington. No que tange ao paradigma cepalino, o conjunto de ideias-força que se destacam envolve a relação entre centro e periferia, a orientação do desenvolvimento para dentro, o papel da tecnologia, a industrialização substitutiva e o papel do Estado. $\mathrm{O}$ autor argumenta que o esgotamento progressivo do desenvolvimento latinoamericano se deve à ausência de um pacto social e político redistributivo que levou o Estado a um viés onipresente, centralista e cativo (IGLESIAS, 2010). Esse viés do Estado latinoamericano levou ao abandono desse modelo e a adoção do modelo advindo do consenso de Washington, que caracterizava o Estado como minimalista e prescindente.

\footnotetext{
Estimou-se que abundavam os argumentos para desqualificar o Estado como mecanismo de distribuição de recursos, principalmente relativos à sua ineficiência, corrupção, clientelismo e excesso burocrático. Isto levou a patrocinar um Estado minimizado, o que significou o fechamento de instituições de política e o corte de seu intervencionismo excessivo (IGLESIAS, 2010, p. 49).
}

Para o economista, essas discussões levam a um novo conceito de Estado no âmbito da América Latina, que teria como objetivos (i) tornar viável a eficiência do mercado; (ii) impulsionar a capacidade produtiva; (iii) se responsabilizar pela diminuição das desigualdades sociais; (iv) se relacionar com as empresas privadas buscando gerar dividendos econômicos e sociais; (v) fortalecer a sociedade civil; (vi) orientar e formular as políticas de inserção internacional; (vii) promover a inovação tecnológica; (viii) promover um processo de reflexão pelos setores público e privado que permita enfrentar os desafios e aproveitar as oportunidades da globalização; (ix) projetar tendências de longo prazo e se basear nelas para estabelecer as estratégias de desenvolvimento; e, (x) promover os grandes consensos nacionais (IGLESIAS, 2010). Para alcançar esses objetivos o autor identifica alguns requisitos básicos, a saber: (i) um sistema democrático robusto; (ii) criação de um serviço civil 
Revista Economia e Desenvolvimento, v. 25, n. 2, 2013.

profissional; (iii) melhorar a capacidade de gestão do gasto público; e, (iv) superar as hipotecas ideológicas e a lógica que reduz a questão a um simples problema técnico.

Ao discutir a questão da reforma do Estado, Pereira (1997) afirma que essa reforma envolve quatro problemas principais, a saber: a delimitação do tamanho do Estado, a redefinição de seu papel regulador, o resgate da governança ou capacidade de implementar as decisões políticas tomadas pelo governo e o resgate da governabilidade, entendida como a capacidade de intermediar interesses, garantir legitimidade e governar.

Os problemas colocados por Pereira remetem à discussão promovida por Arienti (2003) ao tratar das experiências de reforma dos Estados com base nas hipóteses de Jessop sobre as formas e funções do Estado capitalista e à crítica a essas hipóteses. Para Jessop (1998) apud Arienti (2003, p. 98).

[...] dado que o Estado Keynesiano e do regime de bem-estar social foi o tipo que se combinou estruturalmente e estrategicamente com o regime de acumulação e modo de regulação fordista, o Estado Schumpeteriano e do regime social pró-trabalho tem a tendência de se combinar com as variáveis pós-fordistas.

Arienti (2003), ao discutir o assunto, nos remete a dois autores principais. Por um lado cita Schumpeter, que acreditava na inovação e no advento de novas tecnologias como indutor do desenvolvimento. Por outro lado, cita Keynes, que, por sua vez, acreditava na intervenção governamental e no nível de investimento empregado em dada economia.

As ideias de Keynes começaram a ser formuladas no decorrer das crises recorrentes pelas quais vinha passando o capitalismo, que culminam na grande crise dos anos 30. Essas crises colocaram em cheque a capacidade da 'mão invisível' de Adam Smith em equilibrar as forças do mercado e possibilitar a geração e distribuição da riqueza.

Nesse contexto, Keynes propõe sua teoria geral, com vistas a tentar contornar os problemas existentes na economia neo-clássica e 'salvar' o capitalismo. Keynes rejeitava a noção de que a taxa de juros igualaria automaticamente a poupança ao investimento, fazendo com que a demanda agregada se igualasse à oferta agregada. Sua divergência em relação à doutrina neo-clássica envolvia a alegação de que o nível de renda agregada era mais influente para o volume de poupança que a taxa de juros, além disso, argumentava que a poupança e o investimento não determinavam a taxa de juros (HUNT, 2005). 
O discurso desenvolvimentista, a prática orçamentária e a efetividade do Estado enquanto indutor do desenvolvimento: um estudo no estado de Santa Catarina/Brasil.

Com relação às causas das depressões pelas quais o capitalismo passa, Keynes acreditava, segundo Hunt (2005, p. 396), que "a principal causa de uma depressão era, [...] a incapacidade de os capitalistas encontrarem oportunidades de investimento suficientes para compensar os níveis cada vez mais altos de poupança gerados pelo crescimento econômico". Para solucionar esse problema, Keynes propôs a interferência do governo, alegando que nos momentos em que a poupança superasse o investimento, o governo poderia tomar emprestado o excesso de poupança e gastar o dinheiro em projetos socialmente úteis, que não aumentassem a capacidade produtiva da economia e, ao mesmo tempo, não diminuísse as oportunidades de investimentos no futuro (HUNT, 2005).

Os autores pós-keynesianos, por sua vez, avaliam a riqueza e crise com base em medidas de rentabilidade esperada de um ativo, no reconhecimento social do valor desse ativo e nas variações esperadas em seu poder de compra. Nesse sentido, as organizações deveriam se voltar a análises ligadas a determinação de preços, a determinação sobre no que investir e como investir, a uma ponderação entre recursos internos e externos e, a consideração de que os recursos externos acabariam por ditar o ritmo dos investimentos (FEIJÓ, 1989). Os autores pós-keynesianos acreditavam no fato de que em um mundo de incerteza, as expectativas de curto e longo prazo desempenhavam um papel importante nas decisões sobre produção e investimento.

Se por um lado Schumpeter acreditava em inovação, Keynes atribuiu valor ao estado de confiança do mercado, como sendo relevante para as decisões de investimento a longo prazo (FEIJÓ, 1989). Ou seja, a teoria de Keynes era voltada ao investimento, enquanto a de Schumpeter à tecnologia.

Independente da abordagem da questão, ambos os autores (Keynes e Schumpeter) alegam ser importante a participação do Estado para o desenvolvimento, uma vez que a intervenção do Estado poderia aumentar o estado de confiança do mercado, conforme descrito por Keynes, ou fomentar a inovação tecnológica, na visão de Schumpeter. No caso de presente estudo, busca-se analisar a questão com base nas diretrizes propostas no Plano Catarinense de Desenvolvimento - SC 2015, uma vez que esse plano envolve questões relativas a economia, ao meio-ambiente, a sociedade, a tecnologia e a política pública. Serão analisados os impactos dos recursos alocados pelo Estado, via orçamento, para o desenvolvimento econômico e social de Santa Catarina. 
Revista Economia e Desenvolvimento, v. 25, n. 2, 2013.

\subsection{Orçamento público no Brasil e Performance-based Budgenting - PBB}

O termo orçamento pode ser definido como um plano abrangente, considerando todas as fases das operações de um dado negócio, com foco em um período futuro definido. Lunkes (2009) argumenta que o orçamento pode ser entendido com o um plano de longo prazo, que busca abranger tanto aspectos financeiros quanto não financeiros, funcionando como um direcionamento a ser seguido pelas organizações em períodos futuros.

No caso do setor público brasileiro, a Constituição de 1988 instituiu três instrumentos para planejamento e implementação de políticas públicas, a saber: a Lei do Plano Plurianual PPA, a Lei das Diretrizes Orçamentárias - LDO - e a Lei do Orçamento Anual - LOA. O PPA se constitui em uma síntese do planejamento de toda a administração pública, e serve de orientação para a elaboração dos demais planos e programas de governo, de forma regionalizada, envolvendo as diretrizes, os objetivos e as metas para despesas de capital; as despesas decorrentes das despesas de capital, e; os programas de duração continuada. A LDO, por sua vez, compreende as metas e prioridades da administração pública para o exercício subsequente, bem como orienta a elaboração da LOA, que envolve três orçamentos: o fiscal, o da seguridade social e o de investimento das empresas. Além disso, a Lei de Responsabilidade Fiscal - LRF - ampliou a importância da LDO, atribuindo-lhe novas prerrogativas, dentre elas, a incumbência de disciplinar temas específicos ligados ao equilíbrio entre receitas e despesas públicas, metas e riscos fiscais, programação financeira e cronograma de execução mensal.

Atualmente essa é a configuração da estrutura para planejamento orçamentário no Brasil. Apesar de possuir sua sistemática estabelecida em legislação, conforme citado por Cavalcante (2010), os orçamentos públicos convivem com um fator limitador das escolhas alocativas, sua rigidez. Além disso, quanto maior o tamanho e a abrangência do orçamento, mais ele se torna inflexível e restrito. No caso do setor público, evidencia-se uma tendência à utilização de uma prática de orçamento incrementalista, por meio de ajustes marginais baseadas em períodos anteriores.

No que se refere ao orçamento por desempenho, este é entendido com uma estratégia operacional desenvolvida no âmbito da administração pública gerencial, movimento surgido na década de 1980, devido à crise fiscal que envolveu diversos países nesse período, levando a sociedade a uma maior cobrança na efetividade dos serviços públicos ofertados aos cidadãos (CAVALCANTE, 2010). Sua origem remonta ao modelo planning, programming $e$ budgenting system (PPBS), desenvolvido nos Estados Unidos na década de 1960. A partir 
O discurso desenvolvimentista, a prática orçamentária e a efetividade do Estado enquanto

indutor do desenvolvimento: um estudo no estado de Santa Catarina/Brasil.

desse modelo inicial, foram desenvolvidas inovações no processo orçamentário que culminaram no surgimento do PBB, no início da década de 1990.

Ho (2011), salienta que o PBB agrega valor ao diálogo sobre orçamento durante diferentes fases do processo orçamentário, se tornando um instrumento útil para apoiar a tomada de decisão nesse contexto. Kong (2005), ao tratar do tema, argumenta que a avaliação de desempenho como um mecanismo integrado para planejamento, gestão e orçamentação é ideia antiga. Essa abordagem já fazia parte da administração científica na virada do séc. XIX, sendo que o PBB pode ser entendido como uma reformulação dessas práticas.

Para Cavalcante (2010), o PBB objetiva modificar a elaboração orçamentária, dando ênfase aos resultados ao invés de considerar apenas os mecanismos de controle. Nesse sentido, argumenta que as informações da avaliação dos programas governamentais servem de subsídio para a tomada de decisão alocativa, bem como para o planejamento estratégico e accountability dos gestores responsáveis pelo orçamento.

Para Brumby e Robinson (2005), o PBB é um modelo orçamentário que busca relacionar, por um lado, os recursos alocados aos programas de governo e, por outro, os resultados mensuráveis das políticas públicas, desta forma, permite a geração de informações que auxiliam o processo de tomada de decisão pelos governantes e gestores públicos. No caso do presente estudo, busca-se relacionar, de forma alinhada ao argumento de Brumby e Robinson (2005), os recursos alocados pelo Governo do Estado de Santa Catarina, aos resultados do Produto Interno Bruto do Estado, sendo este o foco do estudo de caso a ser apresentado na seção 4 .

\section{METODOLOGIA}

O presente estudo busca realizar uma análise a partir de duas abordagens. Inicialmente utiliza-se de abordagem qualitativa, pois busca a compreensão de significados em contexto específico, visando entender o objeto de estudo por meio de classificações (LYRIO; DELLAGNELO, LUNKES, 2013). Nesse caso, a classificação utilizada é baseada nas teorias sobre desenvolvimento Keynesianas e Schumpeterianas, que são cotejadas com as dimensões e estratégias constantes no Plano Catarinense de Desenvolvimento.

Após a etapa qualitativa, passa a adotar uma abordagem quantitativa, quando da análise dos recursos alocados no orçamento do Estado de Santa Catarina. A ideia do uso de uma abordagem quantitativa está calcada no entendimento de que adota uma abordagem 
Revista Economia e Desenvolvimento, v. 25, n. 2, 2013.

estruturada para o estudo da sociedade, sendo essa tendência um produto dos métodos a ela associados (BRYMAN, 1988).

No que tange ao levantamento dos dados da pesquisa, foi utilizada análise documental do Plano Catarinense de Desenvolvimento, e análise dos dados orçamentários do Estado de Santa Catarina, obtidos junto à Diretoria de Planejamento Orçamentário - DIOR, da Secretaria de Estado da Fazenda, e posteriormente tratadas com o uso de planilhas Excel®. Buscou-se analisar a relação entre os valores orçados e empenhados no período, bem como a evolução dos recursos empenhados em cada uma das dimensões propostas no Plano Catarinense de Desenvolvimento.

Os dados referentes ao orçamento foram coletados de forma direta, por meio da extração dos mesmos do Sistema de Gestão Fazendária - SIGEF - via Discoverer ferramenta de Business Intelligence da Oracle Corporation utilizada pelo Estado de Santa Catarina. Utilizaram-se como série histórica os dados referentes aos anos de 2003 a 2012, e foram utilizadas duas informações principais: (i) os valores da dotação inicial do orçamento de cada ano; e, (ii) os valores empenhados a cada ano. Os valores orçamentários, organizados por funções do Estado e programas de governo, foram cotejados com as diretrizes do Plano Catarinense de Desenvolvimento, conforme apresentado na seção 4. Finalmente, os dados do orçamento foram cotejados com os dados do Produto Interno Bruto do Estado, por meio da análise da tendência linear das variáveis selecionadas (recursos empenhados e evolução do PIB).

\section{APRESENTAÇÃO E ANÁLISE DOS DADOS}

A presente seção busca, inicialmente, apresentar os aspectos inerentes ao Plano Catarinense de Desenvolvimento - SC 2015. Em seguida busca analisar o uso do orçamento enquanto instrumento para implementação de políticas públicas, por meio dos investimentos do Estado nas áreas de atuação constantes neste plano. Finalmente, busca cotejar os dados orçamentários com os dados do PIB do Estado de Santa Catarina.

\subsection{As estratégias e diretrizes do Plano Catarinense de Desenvolvimento}

O Plano Catarinense de Desenvolvimento, proposto em 2005, tinha como principal objetivo a introdução, na administração pública catarinense, de um processo de planejamento 
O discurso desenvolvimentista, a prática orçamentária e a efetividade do Estado enquanto

indutor do desenvolvimento: um estudo no estado de Santa Catarina/Brasil.

de longo prazo (SANTA CATARINA, 2005b). Com este plano buscava-se (i) estabelecer os fundamentos para a promoção do desenvolvimento sustentável e equilibrado do Estado; (ii) definir as diretrizes nas áreas de atuação do Estado, e; (iii) formular as estratégias para que as diretrizes sejam alcançadas (SANTA CATARINA, 2005, p.12).

\begin{tabular}{|l|l|l|}
\hline \multicolumn{1}{|c|}{ DIMENSÃO } & \multicolumn{1}{|c|}{ DESCRIÇÃO DA DIMENSÃO } & \multicolumn{1}{c|}{ ÁREA DE ATUAÇÃO } \\
\hline ECONOMIA E MEIO & $\begin{array}{l}\text { Ações estratégicas do governo para garantir o } \\
\text { AMBIENTE } \\
\text { competitividade sistêmica do Estado. }\end{array}$ & $\begin{array}{l}\text { Infra-estrutura } \\
\text { Iniciativas empreendendoras } \\
\text { Agricultura e meio ambiente }\end{array}$ \\
\hline SOCIAL & $\begin{array}{l}\text { Políticas públicas e mecanismos para garantir o } \\
\text { acesso aos direitos básicos e a inclusão social de } \\
\text { todos os catarinenses no processo de } \\
\text { desenvolvimento. }\end{array}$ & $\begin{array}{l}\text { Saúde } \\
\text { Assistência social, trabalho e renda } \\
\text { Educação e cultura } \\
\text { Segurança }\end{array}$ \\
\hline TECNOLOGIA & $\begin{array}{l}\text { Apoio à ciência e à inovação tecnológica como } \\
\text { forma de promover o desenvolvimento } \\
\text { sustentável. }\end{array}$ & Ciência, tecnologia e inovação \\
\hline POLÍTICA PÚBLICA & $\begin{array}{l}\text { Gestão pública ética e comprometida com a } \\
\text { qualidade dos serviços. }\end{array}$ & Gestão pública \\
\hline
\end{tabular}

Figura 1: Dimensões e áreas de atuação do Estado de Santa Catarina

Fonte: Plano Catarinense de Desenvolvimento - SC 2015

Tendo sido construído a partir de uma perspectiva de elaboração de cenários para o período de 2007 a 2015, o plano levou em consideração aspectos como a concentração em ações de responsabilidade do Estado; a instrumentalização da coordenação dos programas e ações setoriais e regionais, e; a criação de condições para efetivação das ações regionais. Uma vez que busca incorporar a complexidade do sistema sócio-econômico catarinense, adquire um caráter multisetorial. Nesse sentido, extrapola o âmbito de atuação de uma determinada Secretaria Setorial ou Regional, evitando a fragmentação e sobreposição de iniciativas, além da pulverização dos recursos públicos alocados às ações (SANTA CATARINA, 2005b).

As dimensões propostas no Plano Catarinense de Desenvolvimento vão ao encontro do que Pereira (1997) argumenta como integrantes dos componentes que levarão o Estado Social-Liberal ao séc. XXI. Conforme o autor, um desses quatro componentes é justamente a transformação do Estado em "[...] um promotor da capacidade de competição do país a nível internacional ao invés de protetor da economia nacional contra a competição internacional" (PEREIRA, 1997, p. 18).

Essa tendência do Plano Catarinense de Desenvolvimento se evidencia na dimensão Economia e Meio Ambiente, sendo também corroborado pela afirmação de Arienti, quando este afirma que “[...] em termos de política macroeconômica [...] há, assim, um deslocamento 
Revista Economia e Desenvolvimento, v. 25, n. 2, 2013.

do objetivo do pleno emprego como prioridade de política econômica para uma ênfase em criar condições de competitividade" (ARIENTI, 2003, p. 104).

A dimensão Economia e Meio Ambiente está baseada na sustentabilidade econômica, ambiental e social. Nesse sentido, e de forma alinhada à argumentação supracitada, busca "[...] garantir maior competitividade aos sistemas produtivos do Estado" (SANTA CATARINA, 2005b, p. 21). No que tange às áreas de atuação do Estado, a questão da infraestrutura diz respeito aos sistemas de logística de transporte de cargas e passageiros, bem como ao acesso aos serviços de energia elétrica, gás natural, telefonia e saneamento. A questão das iniciativas empreendedoras, por sua vez, busca contribuir para o desenvolvimento dos empreendimentos já instalados no Estado, bem como para criação de políticas atrativas à instalação de novas empresas e fomento ao ensino técnicoprofissionalizante. Finalmente, no que tange à questão da agricultura e meio ambiente, envolve a melhoria da qualidade de vida no interior, com vistas a evitar o êxodo rural e elevar a competitividade os produtos agropecuários do Estado (SANTA CATARINA, 2005b).

Ainda em relação à competitividade do Estado, as dimensões propostas também vão ao encontro de uma política de cunho Schumpeteriano, principalmente no que tange à dimensão Tecnologia. Para Arienti (2003), políticas de cunho Schumpeteriano geralmente atuam a partir da oferta, no sentido de promoção da capacidade inovativa das organizações e de sua difusão para as cadeias de produção, visando o aumento do poder competitivo em mercados de grande concorrência. Além disso, a intenção de evitar a sobreposição de iniciativas constantes no plano vai ao encontro da argumentação de Suzigan e Furtado, quando afirmam que "[...] seria inconcebível, e muito provavelmente impossível, implementar uma estratégia de desenvolvimento industrial fundada em inovação sem que o conjunto de instituições envolvidas estivesse operando em sincronia, articuladamente e com o mesmo foco" (SUZIGAN E FURTADO, 2010, p. 24).

No que tange essa dimensão (Tecnologia), a proposta de atuação do Estado se apoia no incentivo ao desenvolvimento científico e tecnológico, com base no tripé Ciência, Tecnologia e Inovação. Esse incentivo se traduz na ampliação de centros de inovação, incubadoras e condomínios nas regionais do Estado; no apoio à interação universidadeempresa-governo; no estímulo aos programas de pós-graduação em nível de mestrado e doutorado; na promoção do aumento do número de concluintes em cursos superiores nas áreas de conhecimento do novo paradigma tecnológico, e; na ampliação da inclusão digital no Estado (SANTA CATARINA, 2005b). 
O discurso desenvolvimentista, a prática orçamentária e a efetividade do Estado enquanto indutor do desenvolvimento: um estudo no estado de Santa Catarina/Brasil.

Por outro lado, as dimensões de atuação do Estado de Santa Catarina remetem, também, a uma proposta Keynesiana de intervenção na economia. Inicialmente, analisando-se a dimensão Social, evidencia-se que a proposta do Governo busca não somente o aumento na produção de riquezas via aumento da competitividade do Estado, mas também uma melhor distribuição dessa riqueza e uma maior equidade social.

Nesse sentido, no que tange à atuação no campo da saúde, o Estado estabeleceu como diretrizes a redução da mortalidade infantil, a redução dos anos potenciais de vida perdidos, a ampliação do programa de saúde familiar, a intensificação e distribuição da prestação dos serviços de alta e média complexidade, bem como o fortalecimento do controle social por meio de Conselhos Municipais e Estaduais de saúde.

Em relação à assistência social, trabalho e renda, busca aumentar o Índice de Desenvolvimento Humano (IDH) e superar os índices dos Objetivos de Desenvolvimento do Milênio (ODM) em todas as regiões do Estado, bem como consolidar e fortalecer os serviços de assistência social e ampliar a geração de emprego, as oportunidades de trabalho e a renda.

No que tange à educação e cultura, a proposta do governo envolve o acesso dos indivíduos ao conhecimento e a valorização da identidade cultural da sociedade catarinense. Nesse sentido, busca promover a universalização e da qualidade do ensino médio, o aumento do tempo médio de estudo da população, a manutenção de programas de educação continuada dos profissionais da educação, e o estímulo às atividades culturais e a ampliação da infraestrutura destinada ao desenvolvimento desse tipo de atividade.

Na dimensão social ainda existe a atuação do Estado no que se refere à segurança. Nessa questão, busca “[...] melhorar as condições gerais de segurança e tranquilidade da população, fundamentais para garantir a qualidade de vida dos catarinenses" (SANTA CATARINA, 2005b, p. 27). Assim, envolve a ampliação dos serviços de inteligência, implementação de ações de prevenção e combate às drogas, apoio às organizações do terceiro setor na melhoria da segurança pública, redução das taxas de homicídios, capacitação do pessoal efetivo da segurança pública e o aumento no número de vagas no sistema prisional do Estado.

Finalmente, em relação à dimensão das Políticas Públicas, a atuação do Estado envolve a melhoria da gestão pública, no sentido de melhorar a estrutura de governo e a qualidade dos serviços públicos ofertados aos cidadãos. Nesse sentido, as diretrizes envolvem o fortalecimento do processo de descentralização, a busca de soluções para o problema previdenciário do funcionalismo público catarinense, a implementação do governo 
Revista Economia e Desenvolvimento, v. 25, n. 2, 2013.

eletrônico $^{3}$, a consolidação do processo de modernização da gestão, a profissionalização da administração pública e a elevação dos investimentos públicos no Estado (SANTA CATARINA, 2005b).

Pela análise apresentada, pode-se dizer que o discurso desenvolvimentista do Governo do Estado de Santa Catarina, materializado em suas estratégias e diretrizes constantes no Plano Catarinense de Desenvolvimento, está alinhado à visão de um Estado Liberaldemocrático para o séc. XXI, conforme a discussão proposta por Pereira (1997). Percebe-se também uma mescla em políticas de cunho Schumpeteriano, ou seja, de uma busca pelo aumento da competitividade do Estado, ao mesmo tempo em que adota também políticas de cunho Keynesiano, visando à melhoria da equidade social no Estado e o aumento da qualidade de vida de sua população.

\subsection{O uso do orçamento público para implementação das políticas constantes no Plano Catarinense de Desenvolvimento}

Apesar de possuir um discurso promissor, é importante verificar se este discurso se reflete nas práticas orçamentárias do Governo do Estado. Nesse sentido, a presente seção busca analisar a aplicação dos recursos públicos naquelas dimensões e áreas de atuação descritas no Plano Catarinense de Desenvolvimento. Inicialmente apresenta-se a Tabela 1, no qual são apresentados os valores orçados e empenhados em cada uma dessas dimensões.

Em relação à Tabela 1, o total orçado se refere à dotação inicial, estabelecida na LOA, ou seja, reflete o orçamento aprovado para o Estado, formalizado por meio da decretação pelo Poder Legislativo, a sanção pelo Chefe do Poder Executivo e a promulgação por um ou outro poder (GIACOMONI, 2010). O Total Empenhado, por sua vez, é entendido como instrumento de acompanhamento e controle da execução orçamentária, pois “[...] empenhar a despesa significa enquadrá-la no crédito orçamentário apropriado e deduzi-la do saldo da dotação do referido crédito" (GIACOMONI, 2010, p. 306), ou seja, representa a garantia ao credor de que os valores possuem respaldo orçamentário.

\footnotetext{
${ }^{3}$ O Programa de Governo Eletrônico brasileiro tem por objetivo democratizar o acesso à informação, bem como ampliar as discussões e dinamizar a prestação de serviços públicos, por meio da utilização de tecnologias de informação e comunicação. Para saber mais: http://www.governoeletronico.gov.br/o-gov.br
} 
O discurso desenvolvimentista, a prática orçamentária e a efetividade do Estado enquanto indutor do desenvolvimento: um estudo no estado de Santa Catarina/Brasil.

Tabela 1: Valores orçados e empenhados referentes ao período entre 2003 e $2012^{4}$

\begin{tabular}{|c|c|c|c|c|c|}
\hline DIMENSÃO & ÁREA DE ATUAÇÃO & TOTAL ORÇADO & TOTAL EMPENHADO & $\Delta \%$ O X E & $\%$ Part. \\
\hline \multirow[t]{3}{*}{ Economia e Meio Ambiente } & Infra-estrutura & $64.596 .411 .396,00$ & $26.808 .882 .389,36$ & $-58,5 \%$ & $4,1 \%$ \\
\hline & Iniciativas empreendedoras & 19.015.956.900,00 & 3.056.104.649,65 & $-83,9 \%$ & $0,5 \%$ \\
\hline & Agricultura e meio ambiente & $30.831 .746 .352,00$ & $5.528 .043 .426,04$ & $-82,1 \%$ & $0,9 \%$ \\
\hline \multicolumn{2}{|c|}{ Subtotal - Economia e Meio Ambiente } & 114.444.114.648,00 & 35.393.030.465,05 & $-69,1 \%$ & $5,5 \%$ \\
\hline \multirow[t]{4}{*}{ Social } & Saúde & $137.581 .223 .676,00$ & $83.861 .950 .333,76$ & $-39,0 \%$ & $12,9 \%$ \\
\hline & Assitência social, trabalho e renda & $169.938 .542 .724,00$ & $106.555 .538 .417,97$ & $-37,3 \%$ & $16,4 \%$ \\
\hline & Educação e cultura & 242.394.759.696,00 & 120.072.061.677,09 & $-50,5 \%$ & $18,5 \%$ \\
\hline & Segurança & $119.921 .788 .056,00$ & 76.856.206.590,32 & $-35,9 \%$ & $11,9 \%$ \\
\hline \multicolumn{2}{|l|}{ Subtotal - Social } & 669.836.314.152,00 & 387.345.757.019,14 & $-42,2 \%$ & $59,8 \%$ \\
\hline Tecnologia & Ciência, tecnologia e inovação & 10.394.140.452,00 & 2.425.747.622,90 & $-76,7 \%$ & $0,4 \%$ \\
\hline Política Pública & Gestão pública & 406.301.228.064,00 & 222.641.967.631,53 & $-45,2 \%$ & $34,4 \%$ \\
\hline \multicolumn{2}{|l|}{ TOTAL GERAL } & 1.200.975.797.316,00 & 647.806.502.738,62 & $-46,1 \%$ & $100,0 \%$ \\
\hline
\end{tabular}

Fonte: Sistema de Gestão Fazendária - SIGEF

É possível perceber que existe discrepância entre os valores inicialmente orçados e os valores com respaldo orçamentário para execução financeira. No âmbito geral, existe uma variação percentual desfavorável de $46,1 \%$, sendo essa variação potencializada pelas dimensões Economia e Meio Ambiente (69,1\%) e Tecnologia (76,7\%). Essas dimensões são ligadas a uma leitura Schumpeteriana do papel do Estado, justamente pelo fato de se aterem ao aumento da competitividade, sua variação desfavorável pode refletir uma tendência do Estado de Santa Catarina em adotar uma política de cunho Keynesiana, mais voltada ao bemestar social. Essa tendência Keynesiana é reforçada pelo percentual de participação de cada uma das dimensões no total dos recursos empenhados pelo Estado. Enquanto as dimensões Economia e Meio Ambiente e Tecnologia, em conjunto, respondem por 5,9\% dos recursos empenhados no período (2003 a 2012), a dimensão Social responde por 59,8\% e a dimensão Política Pública responde por $34,4 \%$.

Apesar de conter políticas voltadas ao aumento da competitividade, como os programas de Governança Eletrônica e Gestão de Tecnologia de Informação e Comunicação, a maior parte dos recursos referente à dimensão Política Pública está ligada ao apoio administrativo e gestão administrativa dos poderes Executivo, Legislativo e Judiciário, bem como do Ministério Público do Estado, o que leva a constatação de que a máquina pública tem um grande peso no orçamento do Estado, indo na direção contrária da proposta de Pereira (1997) de uma gestão pública eficiente e voltada ao atendimento das demandas da sociedade.

Em se tratando da aplicação dos recursos ao longo do tempo, a série histórica escolhida se deu pela necessidade de analisar os períodos anterior e posterior a implementação do Plano Catarinense de Desenvolvimento. Apesar de idealizado em 2005, sua implementação

\footnotetext{
${ }^{4}$ Para fins de análise, foram considerados os valores orçados e empenhados alinhados às dimensões e áreas de atuação constantes no Plano Catarinense de Desenvolvimento - SC 2015.
} 
se deu a partir de 2007, sendo assim, a série apresenta os valores referentes ao PPA anterior (2004-2007), bem como o posterior (2008-2011), além de apresentar dados de 2003 e 2012, como forma de ampliar o período de análise.

A Figura 2, apresenta a série histórica referente à dimensão Economia e Meio Ambiente. Pela figura, pode-se perceber que houve um ajustamento entre os valores orçados e empenhados no período. Em 2003 havia uma grande discrepância entre esses valores, que passou a diminuir com o passar dos anos, o que reflete uma melhoria no processo de planejamento orçamentário no decorrer do período.

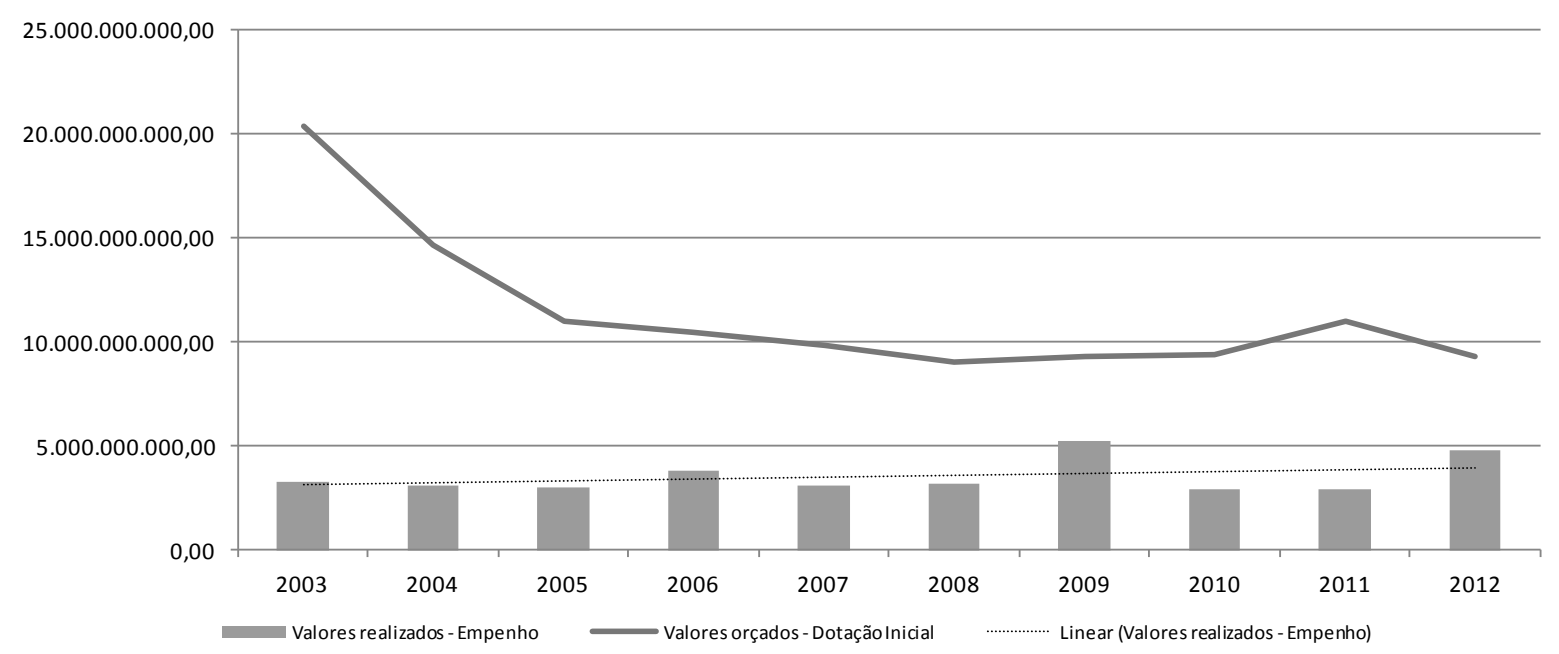

Figura 2: Evolução dos recursos referentes à dimensão Economia e Meio Ambiente Fonte: Sistema de Gestão Fazendária - SIGEF

Em relação ao aumento dos recursos empenhados, a linha de tendência linear reflete um aumento na alocação de recursos para essa dimensão. Em 2003, havia sido empenhado R\$ 3.295.070.743,31, enquanto em 2012 foi empenhado $R \$ 4.761 .759 .683,45$, o que representa um aumento de $44,5 \%$ de recursos empenhados. Salienta-se que do valor total no período analisado a infra-estrutura respondeu por $75,7 \%$ dos recursos empenhados, em sua maior parte decorrente dos investimentos em transporte (infra-estrutura rodoviária, portuária e aeroportuária).

Analisando-se a dimensão Social, a Figura 3 evidencia que a relação entre os valores orçados e empenhados se manteve relativamente equivalente no decorrer do período, chamando a atenção para o ano de 2012, no qual se evidencia uma maior discrepância nessa relação. 
O discurso desenvolvimentista, a prática orçamentária e a efetividade do Estado enquanto indutor do desenvolvimento: um estudo no estado de Santa Catarina/Brasil.

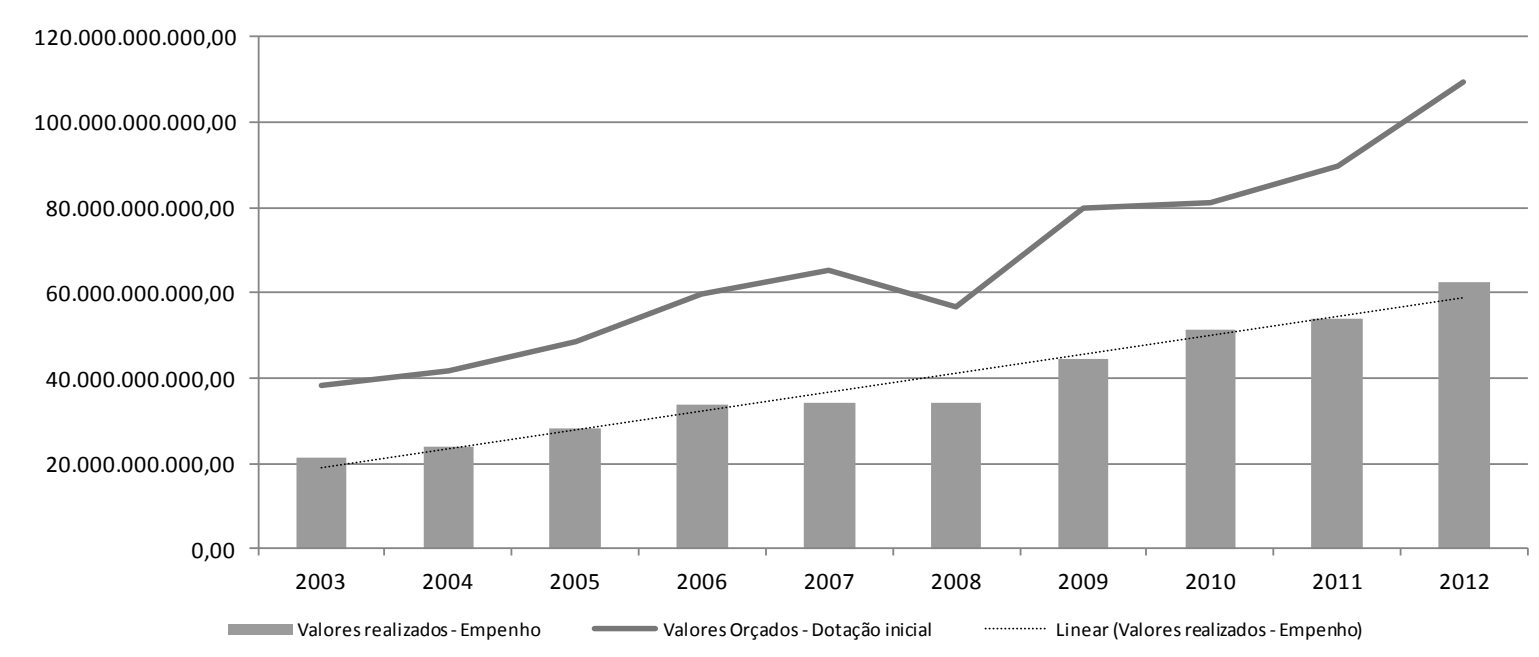

Figura 3: Evolução dos recursos referentes à dimensão Social

Fonte: Sistema de Gestão Fazendária - SIGEF

Tanto na dimensão Economia e Meio Ambiente, quanto na dimensão Social, a linha de tendência linear se apresenta ascendente, mas de forma bem mais acentuada. Nesse caso, em 2003, havia sido empenhado R\$ 21.326.453.442,58, enquanto em 2012, foi empenhado $\mathrm{R} \$$ 62.436.968.516,79, o que representa um aumento de 192,8\%. Esse aumento nos recursos empenhados na dimensão Social reforça a tendência na adoção de políticas de cunho Keynesiano pelo Governo do Estado. A área de educação e cultura se destaca, com um percentual de participação no total do período de $18,5 \%$ dos recursos empenhados. Por outro lado, a área da segurança foi a que menos teve participação, com 11,9\%.

No que tange à dimensão Tecnologia, evidencia-se pela Figura 4 que existe uma grande variabilidade na relação entre os recursos orçados e empenhados. No período correspondente aos anos de 2003 a 2006 houve grande discrepância entre esses valores. Em seguida, nos anos de 2007 e 2008 essa discrepância diminui consideravelmente, mas voltou a crescer nos períodos sub-sequentes, o que revela uma falta de alinhamento entre o planejamento e a execução do orçamento nessa dimensão. Ainda assim, a linha de tendência linear se revela ascendente, indicando um aumento nos recursos empenhados. Da mesma forma como constatado na dimensão Economia e Meio Ambiente, o crescimento nessa dimensão é menos acentuado - apesar de mais representativo, saindo de um valor empenhado em 2003 de $\mathrm{R} \$ 140.647 .769,30$ para um valor de $\mathrm{R} \$ 333.892 .867,38$ em 2012, o que representa um aumento de $137 \%$. Nessa dimensão a atuação do Governo se dá principalmente no fomento à pesquisa, tecnologia e inovação. 


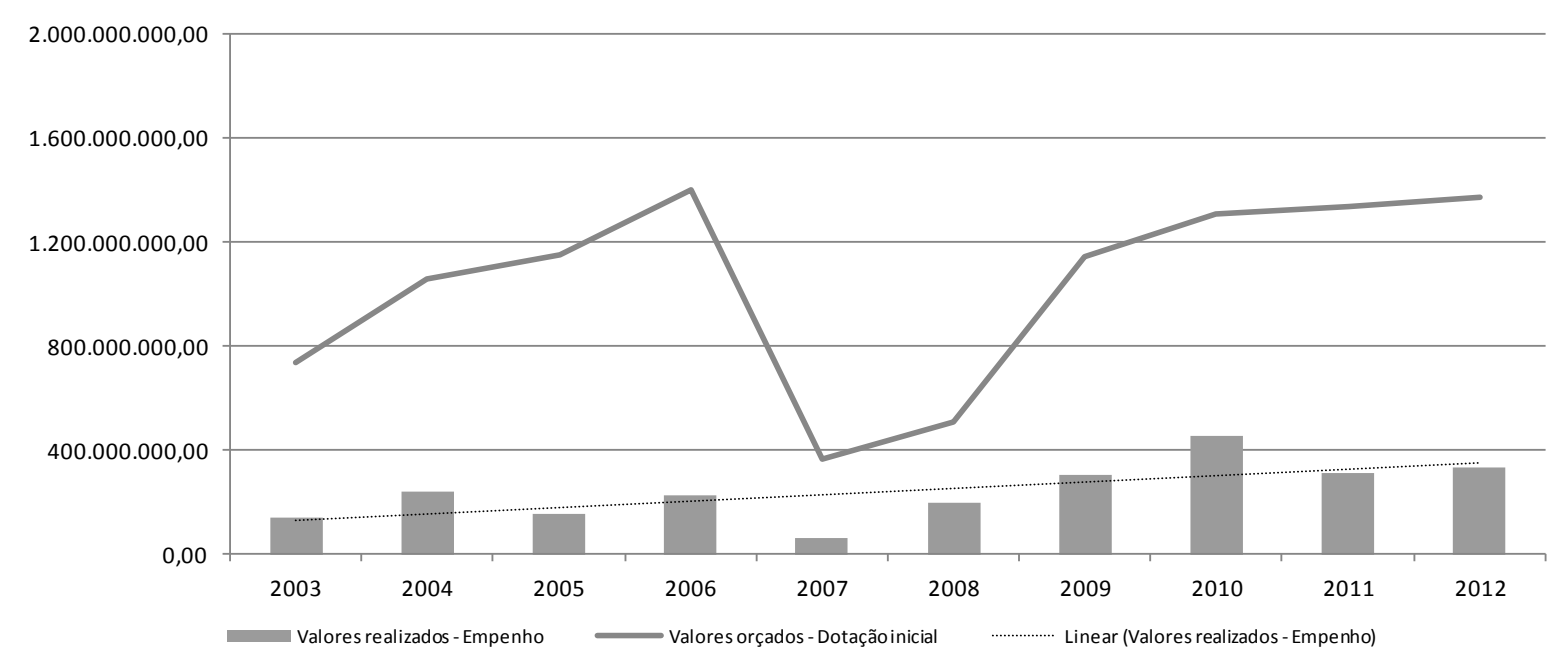

Figura 4: Evolução dos recursos referentes à dimensão Tecnologia

Fonte: Sistema de Gestão Fazendária - SIGEF

Finalmente, em relação à dimensão Política Pública, apresenta-se a Figura 5. Pela figura evidencia-se que, apesar de ainda conter uma discrepância entre os valores orçados e empenhados, nessa dimensão a discrepância se mantém relativamente equilibrada no período analisado. Essa constatação pode ser ligada à utilização excessiva de dados históricos para planejamento do orçamento, que se configura como uma das desvantagens do uso dessa ferramenta, conforme proposto por Boisvert (1999), constatação esta também percebida na análise da dimensão Social. No que tange à tendência linear dos recursos empenhados, da mesma forma como foi evidenciado na dimensão Social, no âmbito da Política Pública, houve grande evolução no período.

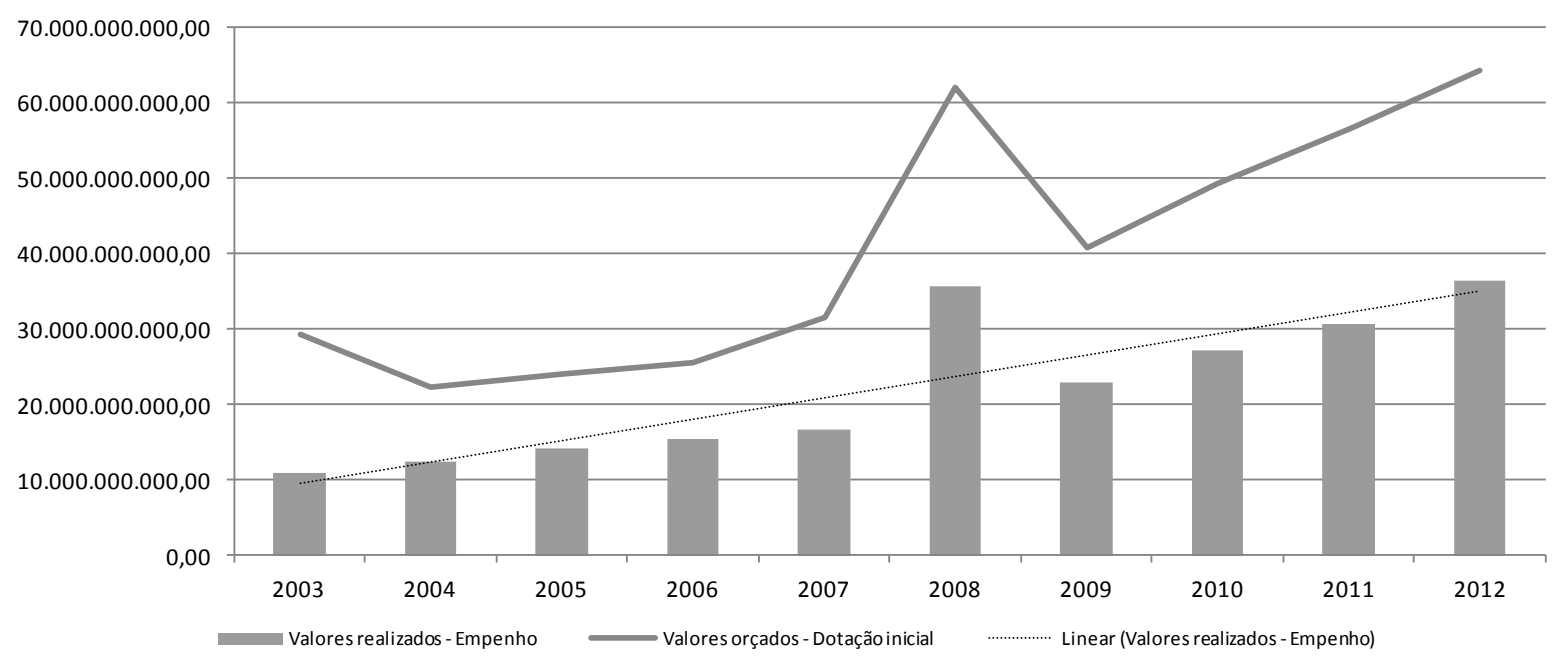

Figura 5: Evolução dos recursos referentes à dimensão Política Pública Fonte: Sistema de Gestão Fazendária - SIGEF 
Em 2003, havia sido empenhado R \$ 10.815.505.620,66, ao passo que em 2012, esse valor elevou-se para $\mathrm{R} \$ 36.502 .107 .930,53$, o que se configura como um aumento de $237,5 \%$ no período. Apesar de refletir um aumento na aplicação de recursos na gestão pública, a maior parte dos recursos está relacionada, conforme citado anteriormente, ao apoio e à gestão administrativa da máquina pública, em seus três Poderes (Executivo, Legislativo e Judiciário) bem como no Ministério Público, o que pode evidenciar o peso da manutenção da máquina pública estadual, uma vez que ao estarem alocados dessa forma, os recursos deixam de incentivar a economia com disponibilidade de crédito, de investimentos em obras, em desenvolvimento tecnológico, entre outros.

Pela discussão aqui apresentada, percebe-se, em âmbito geral, que a prática orçamentária do Estado de Santa Catarina tende a dar maior ênfase às políticas do tipo Keynesianas, buscando aplicar recursos em atividades que gerem melhoria no bem-estar social, como por exemplo, em saúde, educação e segurança. Pereira (1997), por sua vez, argumenta que o Estado Liberal-Democrático para o séc. XXI deve ser um Estado que busca induzir a competitividade, atuando de forma eficiente para o fortalecimento da economia e melhoria da prestação dos serviços à sociedade. Nesse sentido, para dar continuidade à analise a que se pretende o presente estudo, a próxima seção busca analisar a evolução do PIB no Estado, com vistas a verificar a efetividade deste na indução do desenvolvimento.

Conforme citado anteriormente, o Plano Catarinense de Desenvolvimento parece conter em seu discurso políticas de cunho Keynesiano e Schumpeteriano. Por outro lado, ao se analisar a prática orçamentária do Estado, evidencia-se uma tendência em adotar políticas Keynesianas. Arienti (2003) argumenta que deve-se questionar se o Novo Estado atende às demandas na nova dinâmica econômica e social. Nesse sentido, as políticas de cunho Schumpeteriano tendem a atuar na economia a partir da perspectiva da oferta, por meio da promoção da capacidade inovativa e no sentido de buscar alavancar os fatores sistêmicos de competitividade. Por outro lado, as políticas Keynesianas tendem a atuar a partir da perspectiva da demanda, de forma tal que ao tomar emprestado o excesso de poupança o governo poderia gastar esses recursos em projetos socialmente úteis, mas que não afetassem a capacidade produtiva da economia. Com vistas a analisar esta questão, apresenta-se a Figura 6, com a evolução do PIB no Estado. 


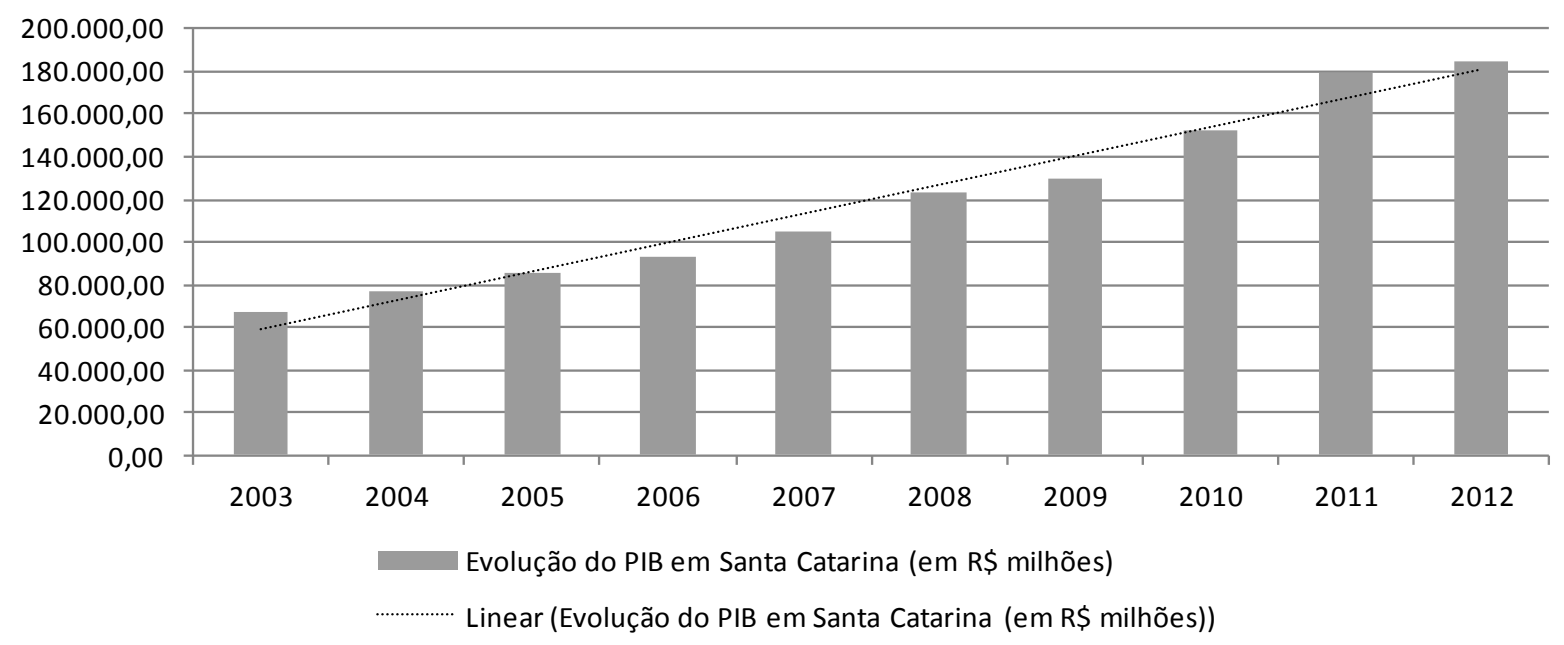

Figura 6: Evolução do Produto Interno Bruto de Santa Catarina Fonte: IBGE ${ }^{5}$

Pela figura, evidencia-se que o PIB no Estado teve considerável crescimento no período analisado. Saindo de $\mathrm{R} \$ 67$ bilhões (aproximadamente) em 2003, para R \$ 184 bilhões (aproximadamente) em 2012. Esse crescimento do PIB representa um aumento de $175 \%$ no período, que se apresenta maior tanto no que tange ao crescimento dos investimentos na dimensão Economia e Meio Ambiente (44,5\%), quanto na dimensão Tecnologia (137\%). Nesse mesmo período, a evolução do PIB nacional - sem considerar os valores de 2011 e 2012, que no caso de Santa Catarina se apresentam como estimativas - foi de $121,8 \%$. Ou seja, pode-se dizer que o PIB do Estado de Santa Catarina, cresceu em proporções maiores que o País.

\section{CONCLUSÕES}

O presente estudo se inseriu no contexto da intervenção do Estado na Economia, por meio de estudo de caso realizado no Estado de Santa Catarina. Para tanto, inicialmente buscou analisar, a partir de uma perspectiva qualitativa, o Plano Catarinense de Desenvolvimento e suas respectivas diretrizes e estratégias. No que tange a essa análise, evidenciou-se no discurso desenvolvimentista catarinense uma mescla de políticas de cunho Schumpeteriano, que atua pelo lado da oferta, buscando gerar uma maior competitividade do Estado por meio

\footnotetext{
${ }^{5}$ Os valores referentes ao PIB para os anos de 2011 e 2012 são estimativas extraídas dos Indicadores Econômico-Fiscais disponibilizadas pela Diretoria de Planejamento Orçamentária - DIOR da Secretaria de Estado da Fazenda de Santa Catarina. (Acesso em 14/04/13) http://www.sef.sc.gov.br/sites/default/files/Indicadores\%20\%20Economico-fiscais\%20-\%20\%202012.pdf.
} 
O discurso desenvolvimentista, a prática orçamentária e a efetividade do Estado enquanto indutor do desenvolvimento: um estudo no estado de Santa Catarina/Brasil.

do desenvolvimento da economia e da inovação tecnológica; e de políticas de cunho Keynesiano, mais voltadas ao bem estar-social.

Por outro lado, ao se analisar, de forma quantitativa, os recursos investidos pelo Governo do Estado no período, percebeu-se uma tendência na implementação de políticas Keynesianas. Essa constatação ficou evidente nos valores orçados e empenhados nas dimensões Social e de Política Pública que juntas responderam por mais de $90 \%$ dos recursos alocados no período. Nesse sentido, e com base em uma inquietação por parte dos autores, buscou-se verificar se "o Plano Catarinense de Desenvolvimento efetivamente vem sendo capaz de induzir o desenvolvimento econômico no âmbito do Estado?"

A resposta a pergunta de pesquisa proposta é positiva, uma vez que houve aumento significativo no PIB do Estado no período em análise (175\%) superior até mesmo ao aumento do PIB nacional (121\%), o que leva a crer que o Plano de Desenvolvimento Catarinense efetivamente vem contribuindo para o desenvolvimento do Estado. Esse crescimento pode ser influenciado, além dos recursos investidos diretamente pelo Governo, por outras políticas de incentivo ao desenvolvimento, que não se refletem no orçamento público. Essa constatação se deve ao fato de que, em sua maioria, as políticas Keynesianas não são voltadas ao crescimento da produção, conforme citado por Hunt (2005), mas sim no sentido de utilização do excesso de poupança para fins de atendimento ao bem-estar social.

Pela análise aqui realizada, percebe-se que houve crescimento no PIB, em níveis acima daqueles existentes no crescimento dos recursos empenhados nas dimensões Economia e Meio Ambiente e Tecnologia. Apesar de se considerar que essas são as dimensões que induzem de forma mais efetiva o desenvolvimento econômico, é necessário ter em conta que a intervenção do Estado na economia não se dá exclusivamente pelos investimentos diretos realizados via orçamento público. Políticas de incentivo à vinda de empresas para a região, como por exemplo, redução de impostos para instalação de fábricas, dentre outros, acabam por interferir na evolução do PIB no Estado, o que pode de certa forma explicar essa divergência.

Como limitações ao estudo, cita-se a não utilização dos dados referentes justamente às políticas de incentivo ao desenvolvimento que não fazem parte do orçamento público, um olhar sobre essas políticas poderia vir a elucidar outras questões que porventura viriam a ajudar no desenvolvimento econômico do Estado. Nesse sentido, sugere-se o desenvolvimento de estudos que tenham em sua abrangência essa questão, com vistas a corroborar ou refutar as conclusões aqui desenvolvidas. 


\section{REFERÊNCIAS}

ARIENTI, W. L. Do estado keynesiano ao estado schumpeteriano. Revista de Economia Política, v. 23, n. 4, p. 97-1113, 2003.

BOISVERT, H. La comptabilité de management: price de décision et gestion. 2. ed. Québec: ERPI Éditions Du Renouveau, 1999.

BOYER, R. Estado, mercado e desenvolvimento: uma nova síntese para o século XXI? Economia e Sociedade, v. 12, 1999.

BRUMBY, J.; ROBINSON, M. Does performance budget works? an analytical review of the empirical literature. . Washington DC: [s.n.]. , 2005

BRYMAN, A. The debate about quantitative and qualitative research. In: BRYMAN, A. (Ed.). Quantity and quality in social research. London: Unwin Hyman, 1988.

CAVALCANTE, P. L. Orçamento por desempenho: uma analise qualitativa comparada dos modelos de avaliação dos programas governamentais no Brasil e nos Estados Unidos. Revista de Gestão USP, v. 17, n. 1, p. 13-25, 2010.

FEIJÓ, C. A. Decisões empresariais em uma economia monetária de produção. In: PAULA, L. F. R. DE; SICSÚ, J. (Eds.). Macroeconomia moderna: Keynes e a economia contemporânea1. Rio de Janeiro: Campus, 1989.

FIORI, J. L. Estados, moedas e desenvolvimento. In: FIORI, J. L. (Ed.). Estados e moedas no desenvolvimento das nações. Petrópolis: Vozes, 1999.

GIACOMONI, J. Orçamento público. 15. ed. São Paulo: Atlas, 2010. p. 369

HO, A. T. PBB in American Local Governments: it's more than a management tool. Public Administration Review, v. 71, n. 3, p. 391-401, 2011.

HUNT, E. K. História do pensamento econômico. 5. ed. Rio de Janeiro: Elsevier, 2005. p. 512

IGLESIAS, E. V. O papel do Estado e os paradigmas econômicos. Revista CEPAL, n. Número especial em português, p. 45-53, 2010. 
O discurso desenvolvimentista, a prática orçamentária e a efetividade do Estado enquanto indutor do desenvolvimento: um estudo no estado de Santa Catarina/Brasil.

KONG, D. Performance-based Budgeting: the U.S. experience. Public Organization Review, v. 5, n. 2, p. 91-107, 2005.

LUNKES, R. J. Manual de orçamento. 2. ed. São Paulo: Atlas, 2009. p. 176

LYRIO, M. V. L.; DELLAGNELO, E. H. L; LUNKES, R. J. O perfil metodológico da produção científica em orçamento público: uma análise do cenário brasileiro na primeira década do século XXI. Revista de Gestão, Finanças e Contabilidade. Salvador, v. 3, n. 1, p. 90-106, jan./abr., 2013.

MARX, K. O Capital. São Paulo: Abril Cultural, 1984.

PEREIRA, L. C. B. A reforma do Estado nos anos 90: lógica e mecanismos de controle. Brasília: Ministério da Administração Federal e Reforma do Estado, 1997. 58 p. (Cadernos MARE da reforma do Estado; v. 1)

POLANYI, K. A grande transformação: as origens da nossa época. Trad. De Fanny Wrobel. Rio de Janeiro, Campus, 1980.

RICARDO, D. Princípios de economia política e tributação. In: CARNEIRO, R. (Ed.). Os clássicos da economia v. 01. São Paulo: Ática, 1997. p. 278.

SANTA CATARINA. Lei Complementar 284, de 28 de Fevereiro de 2005. Estabelece modelo de gestão para a Administração Pública Estadual e dispõe sobre a estrutura organizacional do Poder Executivo.

SANTA CATARINA. Plano Catarinense de Desenvolvimento: SC 2015. Secretaria de Estado do Planejamento - SPG, 2005b.

SANTA CATARINA. Indicadores Econômico-Fiscais. Diretoria de Planejamento Orçamentário - DIOR. Secretaria de Estado da Fazenda, 2013. http://www.sef.sc.gov.br/sites/default/files/Indicadores\%20\%20Economico-fiscais $\% 20$ $\% 20 \% 202012 . p d f$. Acesso em 14/04/13.

SMITH, A. A riqueza das nações: investigação sobre sua natureza e suas causas. In: CARNEIRO, R. (Ed.). Os clássicos da economia v. 01. São Paulo: Ática, 1997. p. 278.

SUZIGAN, W.; FURTADO, J. Instituições e políticas industriais e tecnológicas: reflexões a partir da experiência brasileira. Estudos Econômicos, v. 40, n. 1, p. 7-41, Jan./Mar. 2010. 